\title{
Theoretical study on atmospheric reactions of fluoranthene and pyrene with $\mathrm{N}_{2} \mathrm{O}_{5} / \mathrm{NO}_{3} / \mathrm{NO}_{2}$
}

\author{
Youfeng Wang, Bo Yang*, Jinian Shu, Nana Li, Peng Zhang, Wanqi Sun \\ Research Center for Eco-Environmental Sciences, Chinese Academy of Sciences, Beijing 100085, China
}

\section{A R T I C L E I N F O}

\section{Article history:}

Received 4 May 2015

In final form 19 June 2015

Available online 29 June 2015

\begin{abstract}
A B S T R A C T
It is complex to assign the products obtained from the gas-phase reactions of PAHs with $\mathrm{NO}_{3} / \mathrm{NO}_{2}$ and $\mathrm{N}_{2} \mathrm{O}_{5}$. For this purpose, theoretical calculations are performed. Results show that 2-nitrofluoranthene and 2-nitropyrene are the dominant products for reactions of fluoranthene and pyrene with $\mathrm{NO}_{3} / \mathrm{NO}_{2}$, while 3-nitrofluoranthene and 1-nitropyrene are the major nitration products of $\mathrm{N}_{2} \mathrm{O}_{5} . \mathrm{S}_{\mathrm{N}} 2$ reaction mechanisms are elucidated and homolytic mechanisms are calculated for the first time. Rate constants for reactions of fluoranthene and pyrene with $\mathrm{N}_{2} \mathrm{O}_{5}$ are deduced for the first time, which are $2.50 \times 10^{-27}$ and $2.16 \times 10^{-24} \mathrm{~cm}^{3}$ molecule ${ }^{-1} \mathrm{~s}^{-1}$, respectively at $298 \mathrm{~K}$.
\end{abstract}

(C) 2015 Elsevier B.V. All rights reserved.

\section{Introduction}

Atmospheric polycyclic aromatic hydrocarbons (PAHs) and their nitrated derivatives (NPAHs) are worldwide pollutants and highly potent mutagens, which makes some of them carcinogenic to humans [1-3]. Certain NPAHs even exhibit increased mutagenicity at a concentration significantly lower than that of their parent PAHs [4]. Among them, nitrofluoranthene (NFL) and nitropyrene (NPY) isomers have attracted the most attention because they are typically considered as ubiquitous NPAH atmospheric pollutants [5-8]. These NPAHs can originate from primary emissions (e.g., diesel and power plant emissions) or by the atmospheric oxidation of their parent PAHs. For accurately tracing the source of NPAHs in the atmosphere, it is imperative to investigate the nitration mechanisms of fluoranthene (FL) and pyrene (PY).

Over the past few decades, extensive experimental and theoretical studies have been performed on gas-phase reactions of FL and PY with $\mathrm{N}_{2} \mathrm{O}_{5} / \mathrm{NO}_{3} / \mathrm{NO}_{2}$ [5,9-12]. As a thermal equilibrium exists in the $\mathrm{N}_{2} \mathrm{O}_{5} / \mathrm{NO}_{3} / \mathrm{NO}_{2}$ system, $\mathrm{N}_{2} \mathrm{O}_{5}$ also possibly contributes to nitration products even though $\mathrm{NO}_{3}$ exhibits higher reactivity [12]. Moreover, in experimental studies, it is difficult to completely distinguish between $\mathrm{PAH}$ reactions with $\mathrm{NO}_{3} / \mathrm{NO}_{2}$ and those with $\mathrm{N}_{2} \mathrm{O}_{5}$. Previous studies have reported that the reactions of PAHs, such as naphthalene and methylnaphthalene, with $\mathrm{N}_{2} \mathrm{O}_{5} / \mathrm{NO}_{3} / \mathrm{NO}_{2}$ air mixtures proceed via $\mathrm{N}_{2} \mathrm{O}_{5}$ direct reactions [13,14]. However, the latter studies have experimentally established that the

\footnotetext{
* Corresponding author.

E-mail address: boyang@rcees.ac.cn (B. Yang).
}

reactions possibly proceed in the gas-phase by the initial addition of the $\mathrm{NO}_{3}$ radical, followed by the subsequent addition of $\mathrm{NO}_{2}$. These reactions initiated by $\mathrm{NO}_{3}$ radical were thought to be kinetically equivalent to those reactions with $\mathrm{N}_{2} \mathrm{O}_{5}[15,16]$. Theoretical calculations have been used to clarify the experimental results $[17,18]$. Ghigo et al. [17] have conducted a theoretical study on the reactions of naphthalene with $\mathrm{N}_{2} \mathrm{O}_{5} / \mathrm{NO}_{3} / \mathrm{NO}_{2}$ and determined that the previous kinetic value $\left(\sim 10^{-17} \mathrm{~cm}^{3}\right.$ molecule $\left.{ }^{-1} \mathrm{~s}^{-1}\right)$ [13] should be the rate constant of the $\mathrm{NO}_{3}$-initiated reaction rather than that of the $\mathrm{N}_{2} \mathrm{O}_{5}$ reaction. They have applied the $\mathrm{S}_{\mathrm{N}} 2$ reaction mechanism to the reaction of naphthalene with $\mathrm{N}_{2} \mathrm{O}_{5}$. Ingold and co-workers [19] were the first to propose the $\mathrm{S}_{\mathrm{N}} 2$ reaction mechanism in aprotic solvents. As for FL and PY, to the best of our knowledge, there is no complete computational study for illustrating the reaction mechanisms in $\mathrm{N}_{2} \mathrm{O}_{5} / \mathrm{NO}_{3} / \mathrm{NO}_{2}$ air mixtures thus far. Recently, Zhang et al. [11] have calculated and emphasized the role of water in the gas-phase formation of NPAHs, including NFL and NPY isomers; however, not all of the reaction channels have been calculated. In addition, it is still unclear whether $\mathrm{N}_{2} \mathrm{O}_{5}$ plays a direct role in the reactions with $\mathrm{N}_{2} \mathrm{O}_{5} / \mathrm{NO}_{3} / \mathrm{NO}_{2}$ and whether a particular $\mathrm{NPAH}$ isomer (such as 2-NFL, 3-NFL, 1-NPY, or 2-NPY) is derived from a direct $\mathrm{N}_{2} \mathrm{O}_{5}$ or $\mathrm{NO}_{3}$-initiated reaction. Some researchers have considered that $\mathrm{N}_{2} \mathrm{O}_{5}$ directly reacts with FL to form 2-NFL in aprotic solvents [20]. Zielinska et al. [20] have investigated the reaction of $\mathrm{N}_{2} \mathrm{O}_{5}$ with $\mathrm{FL}$ in $\mathrm{CCl}_{4}$ aprotic solvents and obtained 2-NFL in a high yield at room temperature, which was hypothesized to be formed by the homolytic mechanism. Atkinson et al. [9] have measured the products and kinetics of reactions with FL and PY by adding $\mathrm{N}_{2} \mathrm{O}_{5}$ to $\mathrm{NO}_{2} / \mathrm{PAH} /$ air mixtures with the aim of minimizing the formation of $\mathrm{NO}_{3}$ radicals. They have considered 2-NFL and 

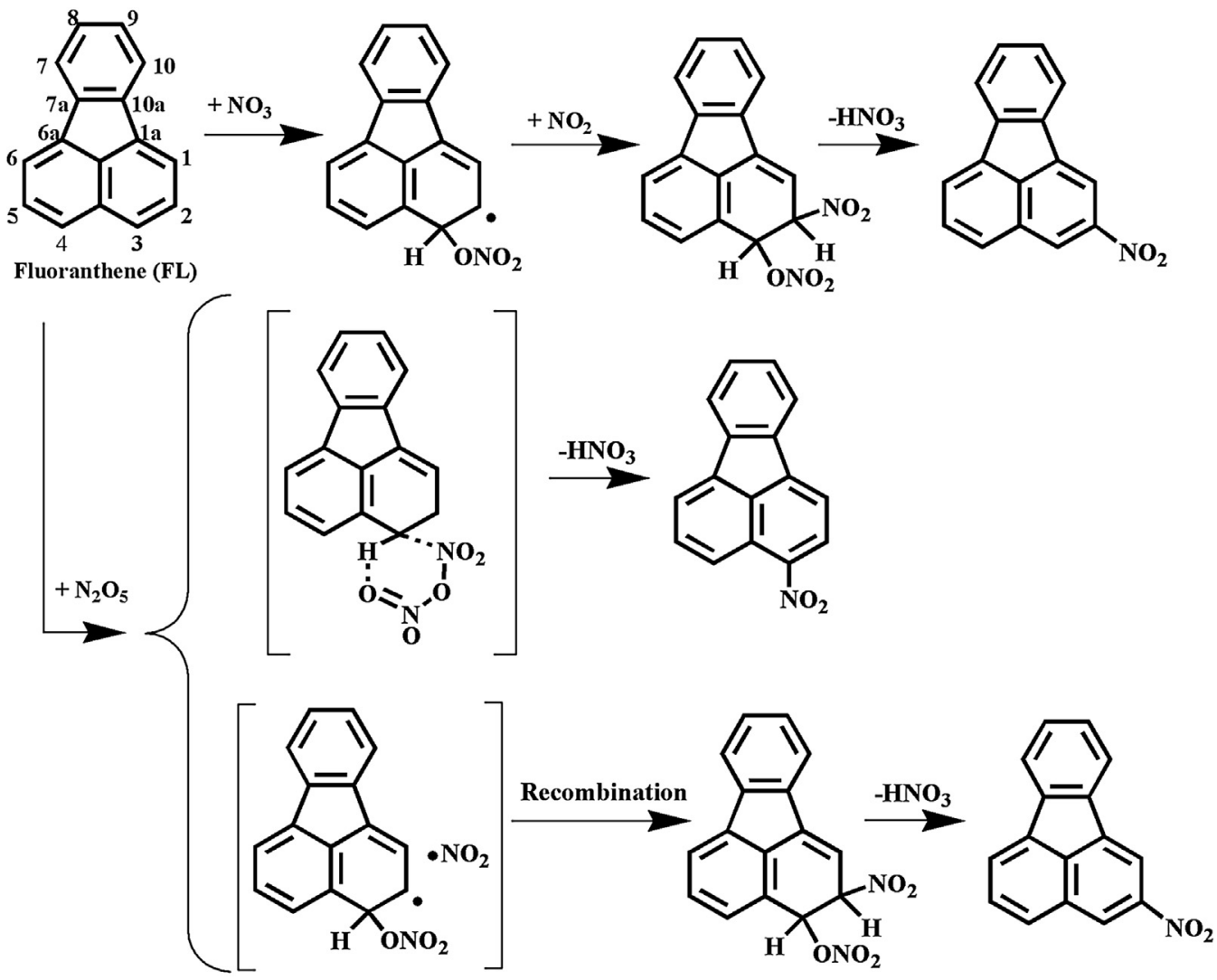

Scheme 1. Reaction scheme for the addition-elimination pathway of fluoranthene (FL) with $\mathrm{NO}_{3} / \mathrm{NO}_{2}$ and two possible reaction mechanisms with $\mathrm{N}_{2} \mathrm{O}_{5}$.

2-/4-NPY to be the products from the $\mathrm{NO}_{3}$-initiated reaction. In addition, the rate constants of the $\mathrm{NO}_{3}$-initiated reaction (in the order of $10^{-17} \mathrm{~cm}^{3}$ molecule ${ }^{-1} \mathrm{~s}^{-1}$ ) were considered to be close to those of the $\mathrm{N}_{2} \mathrm{O}_{5}$ reaction. More recent studies [12,21] have also suggested that 2-NFL and 2-/4-NPY are generated from the gasphase $\mathrm{NO}_{3}$-initiated reactions of $\mathrm{FL}$ and PY, respectively. Hence, the experimental results of the products and kinetics of FL and PY in the reaction with $\mathrm{N}_{2} \mathrm{O}_{5} / \mathrm{NO}_{3} / \mathrm{NO}_{2}$, as well as the postulated reaction mechanisms of $\mathrm{N}_{2} \mathrm{O}_{5}$ with PAHs, need to be further confirmed theoretically.

In this study, to elucidate in detail the formation mechanism of NFL and NPY isomers from the reactions of FL and PY in $\mathrm{N}_{2} \mathrm{O}_{5} / \mathrm{NO}_{3} / \mathrm{NO}_{2}$ air mixtures, respectively, a comprehensive investigation is conducted by density functional theory (DFT). Schemes 1 and 2 show the major reaction pathways for FL and PY with $\mathrm{NO}_{3} / \mathrm{NO}_{2}$ and $\mathrm{N}_{2} \mathrm{O}_{5}$, respectively. The reaction mechanisms and reaction rates are also explored. The process of the addition of $\mathrm{NO}_{3}$ was found to be highly exothermic with an energy barrier significantly lower than that of the direct reaction with $\mathrm{N}_{2} \mathrm{O}_{5}$. Kinetic results rule out $\mathrm{N}_{2} \mathrm{O}_{5}$ as an effective reactant in gas-phase reactions. Thus, isomers associated with $\mathrm{N}_{2} \mathrm{O}_{5}$ reactions such as 3NFL and 1-NPY observed in the atmosphere possibly originate from heterogeneous reactions or primary emissions.

\section{Computational methods}

Electronic structure calculations were conducted by DFT theory using the GaUssian09 program [22]. The geometrical parameters and vibrational frequencies of all stationary points on the reaction potential energy surface (PES) were calculated using the B3LYP $[23,24]$ functional with the standard $6-31 \mathrm{G}(\mathrm{d}, \mathrm{p})$ basis set. The widely used B3LYP method has proven to be an economic and accurate computational model for predicting electronic structure
[25-27]. The minima were confirmed to have positive frequencies, and each transition state had only one imaginary frequency, confirming their location as the maxima (i.e. first-order saddle point) along a single reaction coordinate. In addition, intrinsic reaction coordinate (IRC) paths were calculated to ensure that the given transition states connected the correct minima along the reaction path. A more flexible basis set, 6-311++G(3df,2p), was employed for single-point energy calculations for acquiring more reliable energetic values. The energy derivatives, including gradients and Hessians at geometries of some selected points (30 points on each side) along the minimum energy path (MEP) from $s=-9.216$ to $9.838(\mathrm{amu})^{1 / 2} \mathrm{Bohr}$, were also calculated. The enthalpy of the reaction and Gibbs free energy values were calculated at $298.15 \mathrm{~K}$ and $1.0 \mathrm{~atm}$. Figure 1 shows the structures of FL and PY, with atomic numbering indicated for convenience.

Theoretical rate coefficients were calculated by the canonical variational transition state theory (CVT) [28,29] with a smallcurvature tunneling (SCT) [30] correction using the initial DFT calculations. The rate constant for a bimolecular reaction is expressed by the formula:

$k^{C V T}(T)=\min _{s} k^{G T}(T, s)$

where

$k^{G T}(T, s)=\frac{\sigma}{\beta h} \frac{Q^{G T}(T, s)}{\phi^{R}(T)} e^{-\beta} V_{\mathrm{MEP}}(s)$

In these equations, $k^{G T}(T, s)$ is the generalized-transition-statetheory rate constant at the dividing surface $s, \sigma$ is the symmetry factor, $\beta$ is $\left(k_{B} T\right)^{-1}$ where $k_{B}$ is the Boltzman constant and $h$ is the Planck constant. $Q^{G T}(T, s)$ is the internal partition function of the generalized transition state at $s$, and $\phi^{R}(T)$ is the reactant partition function per unit volume. $V_{\mathrm{MEP}}(s)$ is the classical potential energy along the MEP with its zero of energy at the reactants. Note that 


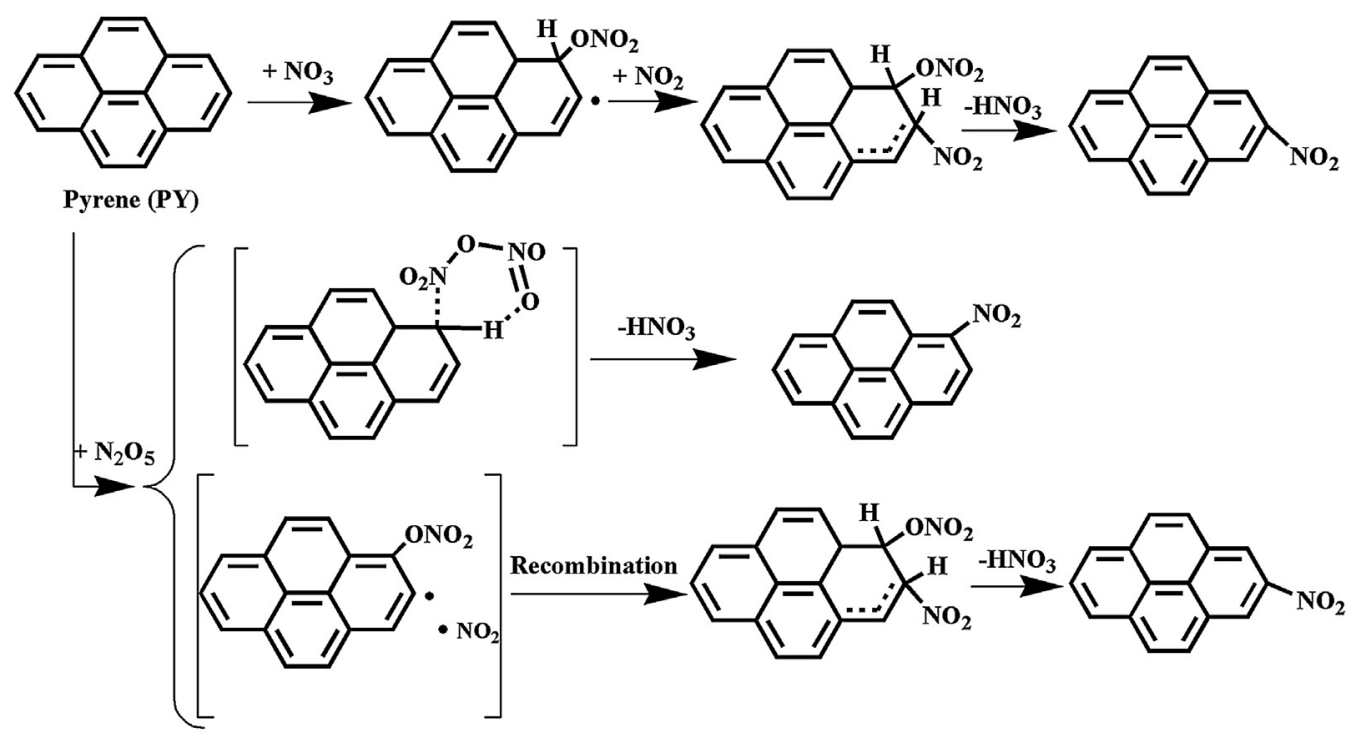

Scheme 2. Reaction scheme for the addition-elimination pathway of pyrene (PY) with $\mathrm{NO}_{3} / \mathrm{NO}_{2}$ and two possible reaction mechanisms with $\mathrm{N}_{2} \mathrm{O}_{5}$.

the energy zeroes for $Q^{G T}(T, s)$ and $\phi^{R}(T)$ are at the saddle point and the bottom of the reactant potential well, respectively. The PES, gradients, and Hessians of the electronic structure at the B3LYP/6$31 \mathrm{G}(\mathrm{d}, \mathrm{p})$ level were directly used to calculate the rate constants over a suitable temperature range (178-398 K). All kinetic calculations were performed using the online VKLAB program package [31].

\section{Results and discussion}

\subsection{Reactions of FL and PY with $\mathrm{NO}_{3}$ radicals}

$\mathrm{NO}_{3}$ radicals are mainly formed via the oxidation of $\mathrm{NO}_{x}$ by $\mathrm{O}_{3}$, with nighttime concentrations from less than 10 to $400 \mathrm{ppt}$, as reported by field observations [32-35]. The first step in the reaction between $\mathrm{NO}_{3}$ and PAHs is either the abstraction of hydrogen or the addition of $\mathrm{NO}_{3}$ to the aromatic ring, the corresponding reaction pathways of which are presented in Figure 2, showing potential barriers $\left(\Delta E^{\neq}\right)$and reaction enthalpies $(\Delta H)$. Table S1 (Supporting information) lists the detailed thermodynamic data. Figures S2 and S3 (Supporting information) show the optimized structures of the transition states involved in these pathways, where the main bond distances have been labeled.

Five transition states for FL (FL-TS1, FL-TS2, FL-TS3, FL-TS7, and FL-TS8 in Figure S1) and three transition states for PY (PY-TS1, PYTS2, and PY-TS4 in Figure S2) were located for the H-abstraction channels. The corresponding products are $\mathrm{HNO}_{3}$ with fluoranthryl (FL-1, FL-2, FL-3, FL-7, or FL-8) and pyrenyl (PY-1, PY-2, or PY-4), respectively, as depicted in Figure $2 \mathrm{a}$ and $\mathrm{c}$. All $\mathrm{H}$-abstraction channels are endothermic by $15.2-15.9 \mathrm{kcal} \mathrm{mol}^{-1}$ with barrier heights of $13.1-14.8 \mathrm{kcal} \mathrm{mol}^{-1}$. The presence of a product complex (PC) explains the slightly lower barriers than its reaction endoergicity, as the processes from PCs to the isolated products are also endothermic. As shown in Table S1, the reaction profile from the reactants to the PCs is endothermic of $9.8-11.0 \mathrm{kcal} \mathrm{mol}^{-1}$. The generated fluoranthryl and pyrenyl isomers may react with $\mathrm{NO}_{2}$ radicals to form NPAHs in the atmosphere. Considering that the reaction barriers of $\mathrm{H}$-abstraction processes are significantly higher than those of $\mathrm{NO}_{3}$

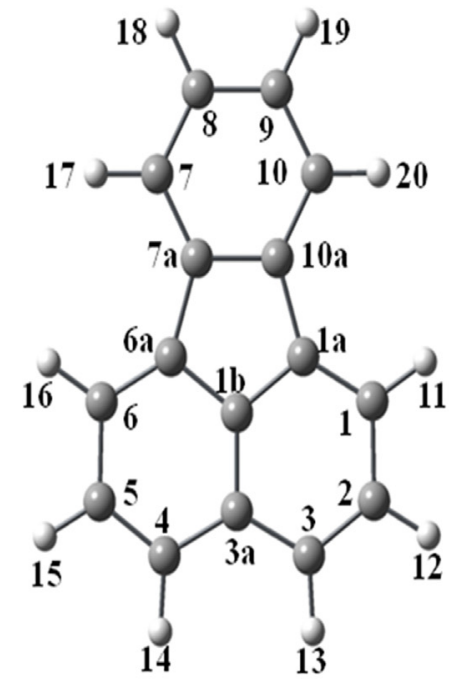

Fluoranthene (FL)

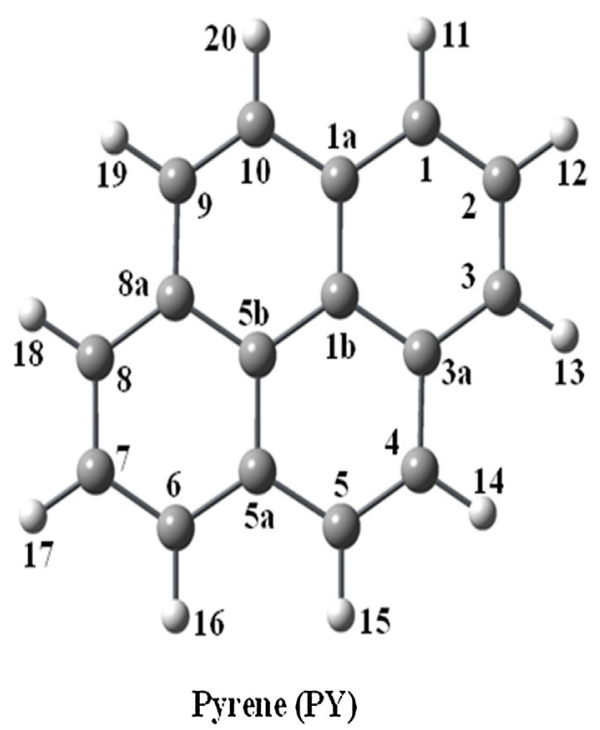

Figure 1. Labeled numbers in the structures of fluoranthene (FL) and pyrene (PY), followed by Onchoke [43]. 
(a)

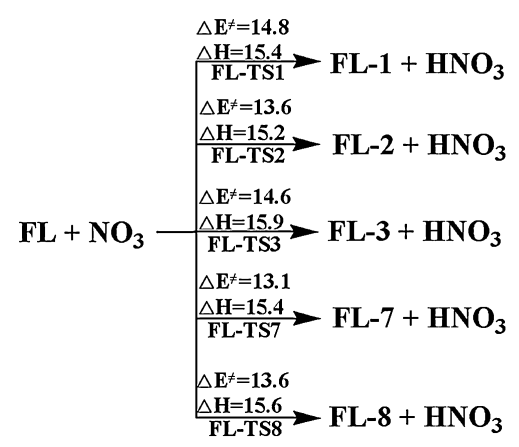

(c)

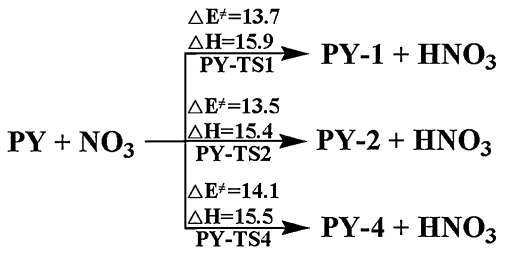

(b)

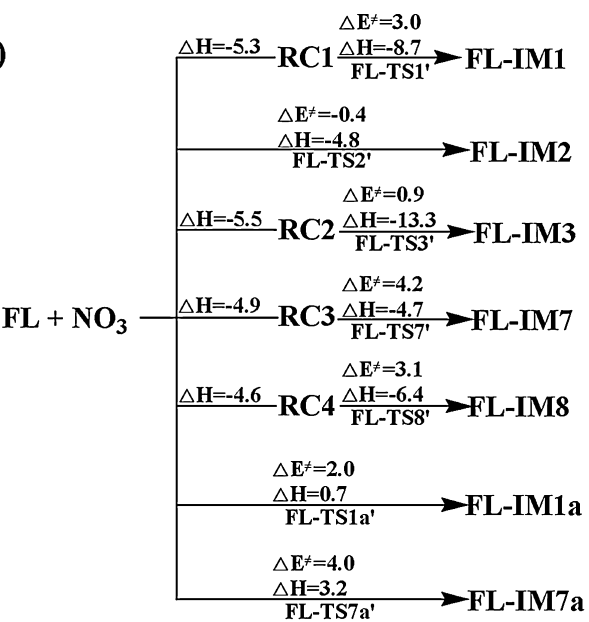

(d)

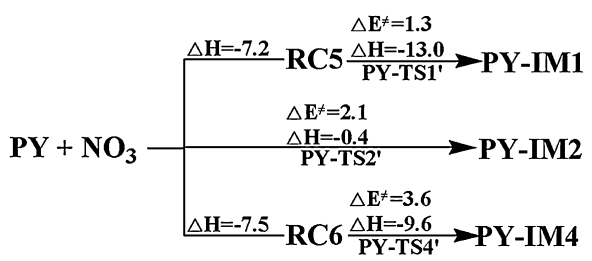

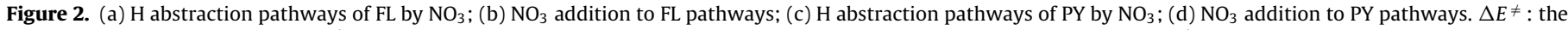
reaction potential barrier $\left(\mathrm{kcal} \mathrm{mol}^{-1}\right)$ at B3LYP/6-311++G(3df,2p)//B3LYP/6-31G(d,p) level; $\Delta H$ : the reaction enthalpy $\left(\mathrm{kcal} \mathrm{mol}{ }^{-1}\right)$ at B3LYP/6-31G(d,p) level.

addition processes, $\mathrm{H}$-abstraction and subsequent reactions are not likely to be the dominant pathways for the reactions of $\mathrm{NO}_{3}$ with FL and PY under ambient atmosphere.

For the addition of $\mathrm{NO}_{3}$, seven different reaction sites on FL and three different reaction sites on PY were revealed. $\mathrm{NO}_{3}$ radicals attack the $\mathrm{C} 1, \mathrm{C} 2, \mathrm{C} 3, \mathrm{C} 7, \mathrm{C} 8, \mathrm{C} 1 \mathrm{a}$, and $\mathrm{C} 7 \mathrm{a}$ atoms in $\mathrm{FL}$ and the $\mathrm{C} 1$, $\mathrm{C} 2$, and $\mathrm{C} 4$ atoms in PY to form $\mathrm{NO}_{3}$-FL (FL-IM $x, x=1,2,3,7,8,1 \mathrm{a}$, and $7 \mathrm{a}$ ) and $\mathrm{NO}_{3}-\mathrm{PY}(\mathrm{PY}-\mathrm{IM} x, x=1,2$, and 4) adducts, respectively, via their corresponding transition states, as shown in Figure $2 b$ and d. The addition of $\mathrm{NO}_{3}$ radicals to the $\mathrm{C} 1 \mathrm{a}$ and $\mathrm{C} 3 \mathrm{a}$ atoms in PY is strictly hindered as $\mathrm{C} 1 \mathrm{a}$ and $\mathrm{C} 3 \mathrm{a}$ are inside the bend of the PY molecule. The energies of most of the transition states are lower than the total energies of the isolated reactants. In particular, prior to the generation of FL-TS1', FL-TS3', FL-TS7', FL-TS8', PY-TS1', and PY-TS4', the existence of a reactant complex (RC) is verified through geometry optimization by the steepest descent method from the end point on the IRC. Figure S3 shows the configurations of the hydrogen-bonded RCs. The barrier heights of the initial reaction steps are derived from the energy difference between the transition states and the RCs (if they exist) or reactants. Both processes, i.e., the formation of RCs from the isolated reactants and formation of $\mathrm{NO}_{3}-\mathrm{PAH}$ adducts from the RCs, are exothermic, releasing energies of 4.6-7.5 and 4.7-13.3 $\mathrm{kcal} \mathrm{mol}^{-1}$, respectively.

These results suggest a stepwise mechanism, which involves the formation of a PC in the exit channel for all the $\mathrm{H}$-abstraction paths and the formation of an $\mathrm{RC}$ in the entrance channel for some $\mathrm{NO}_{3}$ addition paths. The complex mechanism may be significant for the $\mathrm{NO}_{3}$-initated reactions of PAHs. The roles of such complexes were examined in the reactions of $\mathrm{OH}$ radicals with glycolaldehyde [36], glyoxal, and methylglyoxal [37], which exhibited a notable effect on the dynamics.

The reaction Gibbs free energies range from -1.5 to $16.0 \mathrm{kcal} \mathrm{mol}^{-1}$ for $\mathrm{NO}_{3}$ addition pathways. Among these pathways, the values of the Gibbs free energies are negative for the formation of FL-IM3 and PY-IM1, implying that these two pathways possibly occur spontaneously at $298.15 \mathrm{~K}$ and $1.0 \mathrm{~atm}$. In addition, the two processes are exothermic by 13.3 and $13.0 \mathrm{kcal} \mathrm{mol}^{-1}$, demonstrating that the position of the highest electron density (the 3-position in FL and 1-position in PY) is readily attacked by electrophilic or oxidizing reagents. These results indicate that the most favorable pathways are the formation of FL-IM3 and PY-IM1, and their subsequent products 2-NFL and 2-NPY are the dominant oxidation products for the gas-phase reactions of $\mathrm{NO}_{3}$ with $\mathrm{FL}$ and PY, respectively.

Secondary reactions of FL-IM $x$ and PY-IM $x$ with $\mathrm{NO}_{2}$ radicals were also calculated. Figure 3 shows the relevant energies of the stationary points along the reaction profile for the most favorable pathways (reactions of FL-IM3 and PY-IM1 to form 2NFL and 2-NPY, respectively); Figures S4 and S5 show the other pathways and configuration of corresponding transition states, respectively. $\mathrm{NO}_{3}-\mathrm{PAH}$ adducts further react with $\mathrm{NO}_{2}$ without a barrier to form $\mathrm{NO}_{3}-\mathrm{NO}_{2}-\mathrm{PAH}$ intermediates. The energy decrease for the formation of FL-IM3-2 and PY-IM1-2 is 27.3 and $16.9 \mathrm{kcal} \mathrm{mol}^{-1}$, respectively. These intermediates decompose via transition states FL-TS3-2 and PY-TS1-2 with barrier heights of 24.7 and $20.5 \mathrm{kcal} \mathrm{mol}^{-1}$, respectively, generating 2-NFL and 2-NPY with $\mathrm{HNO}_{3}$. The mechanism is summarized as the addition of $\mathrm{NO}_{3}$ and $\mathrm{NO}_{2}$ radicals and elimination of $\mathrm{HNO}_{3}$, which has been reported previously $[11,18,38,39]$. The facile generation of RCs may also lead to the production of 7-/8-NFL and 4-NPY. In fact, low amounts of 4-NPY have been observed in the reactions of FL and PY in $\mathrm{N}_{2} \mathrm{O}_{5} / \mathrm{NO}_{3} / \mathrm{NO}_{2}$ air mixtures $[9,12]$.

\subsection{Reactions of FL and PY with $\mathrm{N}_{2} \mathrm{O}_{5}$}

Tropospheric $\mathrm{N}_{2} \mathrm{O}_{5}$ is also an important gas-phase oxidant, which forms upon the recombination of $\mathrm{NO}_{2}$ and $\mathrm{NO}_{3}$. Typical concentrations of $\mathrm{N}_{2} \mathrm{O}_{5}$ varying from approximately $100 \mathrm{ppt}$ to $10 \mathrm{ppb}$ have been observed [33,34,40-42]. In our study, two different mechanisms were determined for the reactions of $\mathrm{N}_{2} \mathrm{O}_{5}$ with FL and PY. Mechanism (a): an $\mathrm{S}_{\mathrm{N}} 2$-type reaction mechanism in which 
A

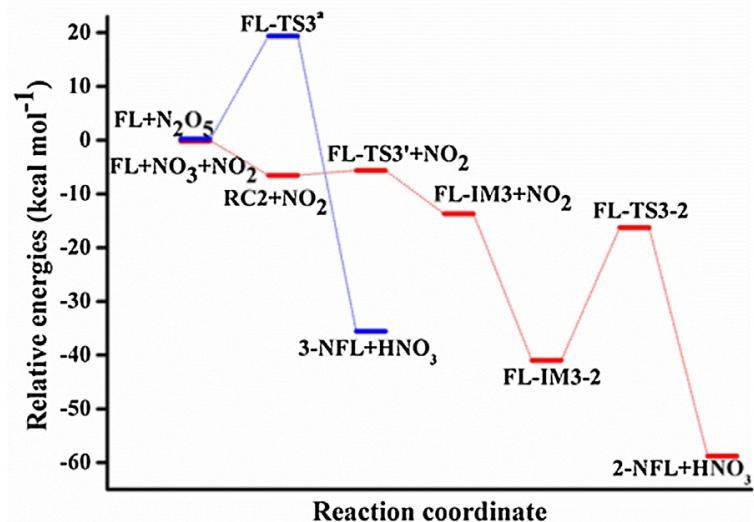

B

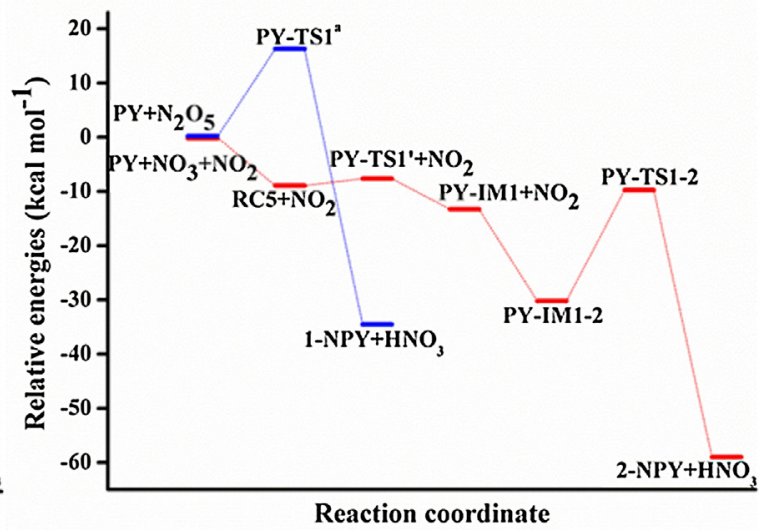

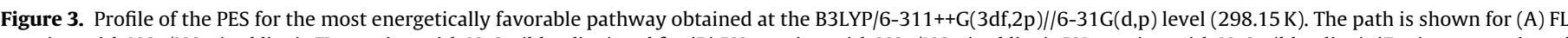

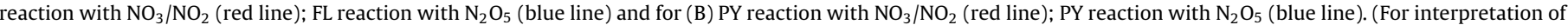
the references to color in this figure legend, the reader is referred to the web version of this article.)

the covalent $\mathrm{N}_{2} \mathrm{O}_{5}$ molecule serves as an electrophile, and mechanism (b): a homolytic mechanism in which the homolysis of $\mathrm{N}_{2} \mathrm{O}_{5}$ generates a radical pair consisting of $\mathrm{ONO}_{2}$ and $\mathrm{NO}_{2}$, which adds to the reactive positions.

In the $\mathrm{S}_{\mathrm{N}}$ 2-type mechanism for the reactions of $\mathrm{FL}$ and PY with $\mathrm{N}_{2} \mathrm{O}_{5}$, eight 6-membered transition states denoted as FL-

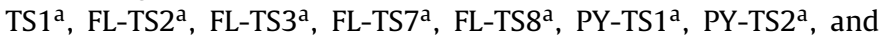
PY-TS4 ${ }^{\text {a }}$ were located successively, producing 1-, 2-, 3-, 7-, and 8NFL and 1-, 2-, and 4-NPY, respectively. The superscript indicates the data from the reaction mechanism (a). Table S2 summarizes the energy barrier $\Delta E^{\neq}$, enthalpy $\Delta H$, Gibbs free energy $\Delta G$, and free-energy barrier $\Delta G^{\neq}$for the reactions of FL and PY with $\mathrm{N}_{2} \mathrm{O}_{5}$. The results show that all eight processes are strongly exothermic with $\Delta H$ values ranging from -36.8 to $-31.7 \mathrm{kcal} \mathrm{mol}^{-1}$. In particular, the pathways involved in the formation of 3-NFL and 1-NPY were found to be the most favorable because of the small barriers of 19.4 and $16.3 \mathrm{kcal} \mathrm{mol}^{-1}$, respectively. By contrast, the formation of 2-NFL and 2-NPY is not facile because of their increased barrier heights of 24.7 and $24.9 \mathrm{kcal} \mathrm{mol}^{-1}$, respectively. The corresponding free energy barriers are in the range of 30.3-35.6 and 26.8-35.1 kcal mol ${ }^{-1}$ for FL and PY in reactions with $\mathrm{N}_{2} \mathrm{O}_{5}$, the maximum of which are close to those of benzene $\left(38 \mathrm{kcal} \mathrm{mol}^{-1}\right)$ and naphthalene ( $\left.36.1 \mathrm{kcal} \mathrm{mol}^{-1}\right)$ calculated by Ghigo et al. [17]. Figure S6 shows the structures of the reactive species corresponding to the most favorable pathways, and Figure S7 shows the configurations of other transition states.

The individual and overall rate constants for the $\mathrm{S}_{\mathrm{N}} 2$ reactions of $\mathrm{N}_{2} \mathrm{O}_{5}$ with FL and PY were computed (Tables S2 and S3). The overall rate constant for the reaction of FL with $\mathrm{N}_{2} \mathrm{O}_{5}$ is denoted as $k_{\mathrm{FL}}=2 k_{1-\mathrm{NFL}}+2 k_{2-\mathrm{NFL}}+2 k_{3-\mathrm{NFL}}+2 k_{7-\mathrm{NFL}}+2 k_{8-\mathrm{NFL}}$, where $k_{1-\mathrm{NFL}}$, $k_{2-\mathrm{NFL}}, k_{3-\mathrm{NFL}}, k_{7-\mathrm{NFL}}$, and $k_{8-\mathrm{NFL}}$ are the corresponding individual rate constants for the generation of 1-NFL, 2-NFL, 3-NFL, 7-NFL, and 8-NFL, respectively. Similarly, the overall rate constant for the reaction of PY with $\mathrm{N}_{2} \mathrm{O}_{5}$ is denoted as $k_{\mathrm{PY}}=4 k_{1-\mathrm{NPY}}+2 k_{2-\mathrm{NPY}}+4 k_{4-\mathrm{NPY}}$. The corresponding total rate constants at $298 \mathrm{~K}$ for $\mathrm{FL}$ and PY with $\mathrm{N}_{2} \mathrm{O}_{5}$ are $2.50 \times 10^{-27}$ and $2.16 \times 10^{-24} \mathrm{~cm}^{3}$ molecule ${ }^{-1} \mathrm{~s}^{-1}$, respectively.

For the homolytic mechanism, the transition state FL-TS $3^{\mathrm{b}}$ (Figure S8) is obtained for the initially formed radical pair (FL-IM3 ${ }^{\mathrm{b}}$, $\mathrm{FL}-\mathrm{ONO}_{2} \cdots \mathrm{NO}_{2}$ radical pair). The radical pair undergoes recombination to generate the nitro-nitrato intermediate FL-IM3-2, which subsequently proceeds via FL-TS3-2 to form 2-NFL. Other transi-

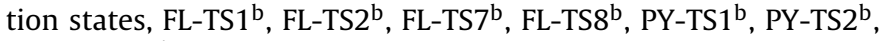
and PY-TS4 ${ }^{\mathrm{b}}$, were also verified by IRC analysis. The superscript indicates the data from the reaction mechanism (b). However, these directly dissociate to form free $\mathrm{NO}_{2}$ radicals and FL-IM1,
FL-IM2, FL-IM7, FL-IM8, PY-IM1, PY-IM2, and PY-IM4, respectively. Then, the re-addition of $\mathrm{NO}_{2}$ to FL-IM $x(x=1,2,7,8)$ and PY-IM $x$ $(x=1,2,4)$ leads to the generation of the nitro-nitrato intermediates, followed by the elimination of $\mathrm{HNO}_{3}$ to form NFL and NPY isomers, respectively. The first step in the homolytic mechanism requires overcoming very high barriers of $32.5-43.2 \mathrm{kcal} \mathrm{mol}^{-1}$ (Table S4). For the favorable pathway through FL-TS3 ${ }^{\mathrm{b}}$, the kinetic constant $\left(k(\mathrm{~T})=3.58 \times 10^{-15} \times \mathrm{T}^{-0.16} \times e^{-13943 / \mathrm{T}}\right) \quad$ is $7.9 \times 10^{-36} \mathrm{~cm}^{3}$ molecule ${ }^{-1} \mathrm{~s}^{-1}$ at $298 \mathrm{~K}$. In contrast with the kinetic results obtained for the $\mathrm{S}_{\mathrm{N}} 2$ reaction, those obtained for the reaction of $\mathrm{N}_{2} \mathrm{O}_{5}$ with PAHs tend to rule out the possibility of a homolytic mechanism. Thus, the homolytic mechanism postulated by Zielinska et al. [20] for the formation of 2-NFL is not possible either thermodynamically or kinetically in the gas phase.

The calculated reaction rate constants of $\mathrm{N}_{2} \mathrm{O}_{5}$ with $\mathrm{FL}$ and PY $\left(2.50 \times 10^{-27}\right.$ and $2.16 \times 10^{-24} \mathrm{~cm}^{-3}$ molecule ${ }^{-1} \mathrm{~s}^{-1}$, respectively, at $298 \mathrm{~K}$ ) are approximately 10 and 7 orders of magnitude less than the experimental values measured by Atkinson et al. [9] Thus, it can be concluded that the $\mathrm{NO}_{3}$-initiated reaction products are actually 2-NFL and 2/4-NPY, but the kinetic values $\left(\sim 10^{-17} \mathrm{~cm}^{3}\right.$ molecule $\left.{ }^{-1} \mathrm{~s}^{-1}\right)$ of $\mathrm{N}_{2} \mathrm{O}_{5} / \mathrm{NO}_{3} / \mathrm{NO}_{2}$ air systems may be assigned to an incorrect nitrating agent between $\mathrm{N}_{2} \mathrm{O}_{5}$ and the $\mathrm{NO}_{3}$ radical [9]. In fact, this result is also consistent with observations reported in a recent study by Zimmermann et al.'s [12] in which they reported that the formations of 2-NFL and 2/4-NPY is significantly greater in the $\mathrm{NO}_{3}$ reaction than in the $\mathrm{N}_{2} \mathrm{O}_{5} / \mathrm{NO}_{3}$ reaction.

\section{Conclusion}

A comparison of the gas-phase reactions of $\mathrm{NO}_{3}$ and $\mathrm{N}_{2} \mathrm{O}_{5}$ with PAHs shows that both $\mathrm{NO}_{3}$ and $\mathrm{N}_{2} \mathrm{O}_{5}$ initially act as electrophilic reagents and attack the position of the highest electron density (the 3-position of FL and 1-position of PY). Then, the $\mathrm{NO}_{3}$-initiated reaction generates the dominant products 2-NFL and 2-NPY (7-, 8-NFL, and 4-NPY are the possible minor products) through the addition of a $\mathrm{NO}_{2}$ radical to the ortho position accompanied by the elimination of $\mathrm{HNO}_{3}$. By contrast, $\mathrm{N}_{2} \mathrm{O}_{5}$ directly reacts with PAHs by electrophilic substitution to form the dominant products 3-NFL and 1-NPY. $\mathrm{NO}_{3}$ addition is highly exothermic with an energy barrier lower than that for the direct reaction with $\mathrm{N}_{2} \mathrm{O}_{5}$, leading to a calculated rate constant of $\sim 10^{-13} \mathrm{~cm}^{3}$ molecule ${ }^{-1} \mathrm{~s}^{-1}$ for the $\mathrm{NO}_{3}$ reaction [11], which is significantly higher than that of the $\mathrm{N}_{2} \mathrm{O}_{5}$ reaction calculated in this study.

By using the theoretical method, this study identifies the different NFL/NPY isomers produced from $\mathrm{NO}_{3}$-initiated and $\mathrm{N}_{2} \mathrm{O}_{5}$ reactions as well as the mechanism and kinetics of the $\mathrm{N}_{2} \mathrm{O}_{5}$ 
reaction, which have not been confirmed before. The obtained results can offer new assistant information for recognizing the source of NPAH pollutants. First, the product assignments show that gas-phase $\mathrm{NO}_{3}$-initiated and $\mathrm{N}_{2} \mathrm{O}_{5}$ reactions with $\mathrm{FL} / \mathrm{PY}$ have their individual specific products. The dominant products for $\mathrm{NO}_{3}-$ initiated reactions are 2-NFL/2-NPY, while those for $\mathrm{N}_{2} \mathrm{O}_{5}$ reactions are 3-NFL/1-NPY. The kinetic data reveal that $\mathrm{N}_{2} \mathrm{O}_{5}$ is not expected to be an effective reactant in gas-phase reactions with PAHs. This result indicates that 2-NFL and 2-NPY can be produced as the major degradation products in the gas-phase reaction of FL and PY in the $\mathrm{N}_{2} \mathrm{O}_{5} / \mathrm{NO}_{3} / \mathrm{NO}_{2}$ air system. 3-NFL and 1-NPY observed in the atmosphere possibly originate from primary emissions or heterogeneous reactions. In addition, because of the different reaction processes, the heterogeneous reactions of FL and PY with $\mathrm{N}_{2} \mathrm{O}_{5} / \mathrm{NO}_{3} / \mathrm{NO}_{2}$ are quite different from the gas-phase reactions under atmospheric conditions, which produces 3-, 8-, 7-, 1-NFL, and 1 -NPY as the major particulate nitration products [21]. However, 2NFL is considered as the dominant particle-bound NPAH measured in ambient atmospheres, which possibly originates mainly from the gas-phase $\mathrm{NO}_{3}$ reaction and condensation on the aerosol surface. The reaction mechanism illustrated in this study may also help to interpret the atmospheric transformation of other PAHs toward $\mathrm{N}_{2} \mathrm{O}_{5} / \mathrm{NO}_{3} / \mathrm{NO}_{2}$.

\section{Acknowledgements}

This work was funded by the National Natural Science Foundation of China (Grant Nos. 21277155 and 21207143) and the Creative Research Groups of China (No. 51221892).

\section{Appendix A. Supplementary data}

Supplementary data associated with this article can be found, in the online version, at doi:10.1016/j.cplett.2015.06.056

\section{References}

[1] S.-C. Chen, C.-M. Liao, Sci. Total Environ. 366 (2006) 112.

[2] H. Lu, L. Zhu, S. Chen, Environ. Pollut. 152 (2008) 569

[3] P.-J. Tsai, H.-Y. Shieh, W.-J. Lee, S.-O. Lai, Sci. Total Environ. 278 (2001) 137.

[4] J.L. Durant, W.F. Busby Jr., A.L. Lafleur, B.W. Penman, C.L. Crespi, Mutat. Res. Genet. Toxicol. 371 (1996) 123.

[5] J.N. Pitts Jr., J.A. Sweetman, B. Zielinska, A.M. Winer, R. Atkinson, Atmos. Environ. 19 (1985) 1601

[6] J.N. Pitts, J.A. Sweetman, B. Zielinska, R. Atkinson, A.M. Winer, W.P. Harger, Environ. Sci. Technol. 19 (1985) 1115.
[7] T. Ramdahl, B. Zielinska, J. Arey, R. Atkinson, A.M. Winer, J.N. Pitts, Nature 321 (1986) 425.

[8] H.A. Bamford, J.E. Baker, Atmos. Environ. 37 (2003) 2077.

[9] R. Atkinson, J. Arey, B. Zielinska, S.M. Aschmann, Int. J. Chem. Kinet. 22 (1990) 999.

[10] R. Atkinson, J. Arey, Environ. Health Perspect. 102 (1994) 117

[11] Q. Zhang, R. Gao, F. Xu, Q. Zhou, G. Jiang, T. Wang, J. Chen, J. Hu, W. Jiang, W. Wang, Environ. Sci. Technol. 48 (2014) 5051.

[12] K. Zimmermann, R. Atkinson, J. Arey, Y. Kojima, K. Inazu, Atmos. Environ. 55 (2012) 431.

[13] J.N. Pitts, R. Atkinson, J.A. Sweetman, B. Zielinska, Atmos. Environ. 19 (1985) 701.

[14] B. Zielinska, J. Arey, R. Atkinson, P.A. McElroy, Environ. Sci. Technol. 23 (1989) 723.

[15] R. Atkinson, E.C. Tuazon, J. Arey, Int. J. Chem. Kinet. 22 (1990) 1071.

[16] L. Wang, R. Atkinson, J. Arey, Environ. Sci. Technol. 44 (2010) 2981.

[17] G. Ghigo, M. Causa, A. Maranzana, G. Tonachini, J. Phys. Chem. A 110 (2006) 13270.

[18] X. Qu, Q. Zhang, W. Wang, Chem. Phys. Lett. 432 (2006) 40.

[19] V. Gold, E. Hughes, C. Ingold, G. Williams, J. Chem. Soc. (1950) 2452 (resumed)

[20] B. Zielinska, J. Arey, R. Atkinson, T. Ramdahl, A.M. Winer, J.N. Pitts, J. Am. Chem. Soc. 108 (1986) 4126

[21] K.Zimmermann, N. Jariyasopit, S.L. Massey Simonich, S. Tao, R. Atkinson, J. Arey, Environ. Sci. Technol. 47 (2013) 8434

[22] M.J. Frisch, et al., Gaussian09, Revision A.02, Gaussian, Inc., Wallingford, CT, 2009.

[23] A.D. Becke, J. Chem. Phys. 98 (1993) 5648

[24] C. Lee, W. Yang, R.G. Parr, Phys. Rev. B 37 (1988) 785.

[25] Y. Pan, R. Wang, Chem. Phys. 367 (2010) 48.

[26] L. Sandhiya, P. Kolandaivel, K. Senthilkumar, J. Phys. Chem. A 117 (2013) 4611.

[27] L. Sandhiya, P. Kolandaivel, K. Senthilkumar, Can. J. Chem. 90 (2012) 384

[28] B.C. Garrett, D.G. Truhlar, J. Am. Chem. Soc. 101 (1979) 4534.

[29] B.C. Garrett, D.G. Truhlar, R.S. Grev, A.W. Magnuson, J. Phys. Chem. 84 (1980) 1730.

[30] Y.P. Liu, D.H. Lu, A. Gonzalez-Lafont, D.G. Truhlar, B.C. Garrett, J. Am. Chem. Soc 115 (1993) 7806

[31] S.-W. Zhang, T.N. Truong, VKLab Version 1.0, University of Utah, 2001.

[32] S. Brown, T. Ryerson, A. Wollny, C. Brock, R. Peltier, A. Sullivan, R. Weber, W. Dube, M. Trainer, J. Meagher, Science 311 (2006) 67.

[33] A. Geyer, R. Ackermann, R. Dubois, B. Lohrmann, T. Müller, U. Platt, Atmos. Environ. 35 (2001) 3619

[34] F. Heintz, U. Platt, H. Flentje, R. Dubois, J. Geophys. Res. Atmos. 101 (1996) 22891.

[35] R. McLaren, R.A. Salmon, J. Liggio, K.L. Hayden, K.G. Anlauf, W.R. Leaitch, Atmos. Environ. 38 (2004) 5837.

[36] A. Galano, J.R. Alvarez-Idaboy, M.E. Ruiz-Santoyo, A. Vivier-Bunge, J. Phys, Chem. A 109 (2005) 169.

[37] A. Galano, J.R. Alvarez-Idaboy, M. Ruiz-Santoyo, A. Vivier-Bunge ChemPhysChem 5 (2004) 1379.

[38] X. Qu, Q. Zhang, W. Wang, Can. J. Chem. 86 (2008) 129.

[39] C.E. Jessen, A. Gross, J. Kongsted, S. Jørgensen, Chem. Phys. 389 (2011) 39.

[40] R. Atkinson, A.M. Winer, J.N. Pitts, Atmos. Environ. 20 (1986) 331.

[41] J. Stutz, B. Alicke, R. Ackermann, A. Geyer, A. White, E. Williams, J. Geophys. Res. Atmos. 109 (2004) D12306.

[42] S.S. Brown, H. Stark, T.B. Ryerson, E.J. Williams, D.K. Nicks, M. Trainer, F.C Fehsenfeld, A. Ravishankara, J. Geophys. Res. Atmos. 108 (2003) D94299.

[43] K.K. Onchoke, Polycycl. Aromat. Comp. 28 (2008) 193. 